\title{
Papers
}

\section{Stressful life events and difficulties and onset of breast cancer: case-control study}

\author{
David Protheroe, Kim Turvey, Kieran Horgan, Eddie Benson, David Bowers, Allan House
}

\begin{abstract}
Objective To determine the relation between stressful life events and difficulties and the onset of breast cancer.

Design Case-control study.

Setting 3 NHS breast clinics serving west Leeds. Participants 399 consecutive women, aged 40-79, attending the breast clinics who were Leeds residents. Main outcome measures Odds ratios of the risk of developing breast cancer after experiencing one or more severe life events, severe difficulties, severe 2 year non-personal health difficulties, or severe 2 year personal health difficulties in the 5 years before clinical presentation.

Results 332 (83\%) women participated. Women diagnosed with breast cancer were no more likely to have experienced one or more severe life events (adjusted odds ratio 0.91, 95\% confidence interval 0.47 to $1.81 ; \mathrm{P}=0.79)$; one or more severe difficulties $(0.86,0.41$ to $1.81 ; \mathrm{P}=0.69)$; a 2 year severe non-personal health difficulty $(0.53,0.12$ to 2.31 ; $\mathrm{P}=0.4$ ); or a 2 year severe personal health difficulty (2.73, 0.68 to $10.93 ; \mathrm{P}=0.16$ ) than women diagnosed with a benign breast lump.

Conclusion These findings do not support the hypothesis that severe life events or difficulties are associated with onset of breast cancer.
\end{abstract}

\section{Introduction}

The belief that the onset of cancer may be associated with a stressful experience is found in the British, French, and United States medical literature at least as far back as $1701 .{ }^{1}$ In a recent survey of South Australian women, $40 \%$ reported that they believed that stress was a cause of breast cancer. ${ }^{2}$ Research into the association, however, has methodological weaknesses. ${ }^{3}$

Four recent studies of breast cancer have used the life events and difficulties schedule, a semistructured interview of proved reliability ${ }^{4}$ two examined the association between stress and relapse, and two examined the association between stress and onset of breast cancer. $^{5-8}$ The results are not clear cut. In the most recent study, Chen et al found that severe life events were associated with breast cancer, with an odds ratio of 11.6 after adjustment for confounders. The result provoked speculation about biological mechanisms for the effect, ${ }^{9}$ and widespread media coverage of the association between stress and cancer followed. ${ }^{10}$

We have attempted to replicate the findings of Chen et al, but with improvements in five areas of study design. Firstly, we included a larger sample of women presenting with a suspicious breast lump. Secondly, we obtained a consecutive series of women from a defined geographical area presenting with a breast lump, to reduce selection bias. Thirdly, we examined more social and physical risk factors for breast cancer to correct for potential confounding. Fourthly, we used two researchers who held regular consensus rating meetings to reduce observer bias. Finally, we examined the effect of the participant's knowledge of diagnosis on reporting of severe life events.

\section{Participants and methods}

\section{Participants}

Outpatient services for diagnosing suspicious breast lumps in Leeds were provided by two NHS trusts at the time of the study (September 1996 to February 1998). The two services were similar, and we identified no obvious systematic bias in general practitioners' referral patterns to the two units. We therefore sited the study in the three clinics that form the service for the west of Leeds. We recruited all women attending breast clinics at Leeds General Infirmary, Chapel Allerton Hospital, and Wharfedale General Hospital, Otley who were to have tissue checked from a suspicious breast lump. Women aged between 40 and 79 years residing at a Leeds address were asked to participate by their surgeon. Exclusions were previous breast cancer and inability to comply with an interview owing to poor English or serious physical or mental illness. We obtained research ethics approval for our study.

\section{Study protocol}

The women were introduced to the research interviewer (DP or KT) immediately after the surgical consultation, and a home interview was arrangedusually for the next day. Written consent was obtained. The life events and difficulties schedule was administered to cover a 5 year period before the clinical presentation. Social and physical risk factors for breast cancer were recorded, and the participants were asked to predict their diagnosis. The women completed the Beck depression inventory. ${ }^{11}$ If the interview reminded them of painful emotional issues, they were offered

\section{Editorial by McGee Department of Liaison Psychiatry, Leeds General Infirmary, Leeds LS1 3EX \\ David Protheroe senior registrar Kim Turvey psychiatric nurse Allan House senior lecturer in psychiatry \\ Department of Surgery, Leeds General Infirmary Kieran Horgan consultant surgeom Edward Benson consultant surgeon \\ Sub Unit of Medical Statistics, Nuffield Institute for Health, University of Leeds LS2 9PL \\ David Bowers medical statistician \\ Correspondence to: D Protheroe, Northern Hospital, Epping, Victoria 3076 Australia dprotheroe@tnh. vic.gov.au}

BMJ 1999;319:1027-30

website extra

The sample size calculation appears on the BMJ's website

www.bmj.com 
appropriate professional counselling. Weekly consensus rating meetings were held, and borderline or unusual events and difficulties were rated over the telephone with one of the originators of the life events and difficulties schedule.

\section{Cancer diagnosis}

Cancer was diagnosed by cytological examination of breast tissue and confirmed by histopathological examination. Participants diagnosed with cancer were cases and those whose biopsy showed normal breast tissue or benign breast disease were controls.

\section{Assessment of life stress}

Events and difficulties were rated according to their severity and content, and difficulties were rated according to their duration. Life events were rated on a four point scale, and severity of difficulties lasting at least 4 weeks was rated on a six point scale. We followed the

Table 1 Characteristics of cases and controls. Values are mean (SD) unless stated otherwise

\begin{tabular}{|c|c|c|c|}
\hline Variable & $\begin{array}{l}\text { Breast cancer } \\
\text { group }(n=106)\end{array}$ & $\begin{array}{l}\text { Control group } \\
(\mathrm{n}=226)\end{array}$ & $P$ value \\
\hline Age & $61.6(10.9)$ & $51.0(8.5)$ & $0.000^{*}$ \\
\hline \multicolumn{4}{|l|}{ Social class† (\%): } \\
\hline I & $10(10)$ & $20(9)$ & \multirow{7}{*}{$0.094 \ddagger$} \\
\hline II & $38(36)$ & $82(36)$ & \\
\hline III non-manual & $28(26)$ & $72(32)$ & \\
\hline III manual & $13(12)$ & $24(11)$ & \\
\hline IV & $11(10)$ & $21(9)$ & \\
\hline V & $3(3)$ & $2(1)$ & \\
\hline VI & $3(3)$ & $4(2)$ & \\
\hline \multicolumn{4}{|l|}{ No of children (\%): } \\
\hline 0 & $15(14)$ & $31(14)$ & \\
\hline 1 & $16(15)$ & $31(13.7)$ & 0.97 \\
\hline 2 & $42(40)$ & $84(37)$ & \\
\hline$\geqslant 3$ & $32(31) \dagger$ & $80(35)$ & \\
\hline Age at birth of first child & $21.3(5.6)$ & $20.5(4.3)$ & $0.500^{\star}$ \\
\hline Age at menarche & $12.8(1.4)$ & $13.0(1.6)$ & $0.200^{*}$ \\
\hline \multicolumn{4}{|l|}{ Menopausal state (\%): } \\
\hline Premenopausal & $14(13)$ & $66(29)$ & \multirow{3}{*}{$0.000 \S$} \\
\hline Perimenopausal & $9(9)$ & $43(19)$ & \\
\hline Postmenopausal & $83(78)$ & $117(52)$ & \\
\hline Age at menopause & $47.7(4.5)$ & $45.6(5.2)$ & $0.001^{\star}$ \\
\hline Lifetime use of oral contraceptives (\%) & 38 & 61 & $0.000 \ddagger$ \\
\hline No of years taking oral contraceptives & $3.0(5.4)$ & $4.2(5.0)$ & $0.065 \S$ \\
\hline \multirow[t]{2}{*}{ No of months breastfeeding } & $(n=90)$ & $(n=195)$ & \\
\hline & $7.4(9.9)$ & $7.4(12.1)$ & $0.990^{*}$ \\
\hline Lifetime use of hormone replacement therapy (\%) & $29(27)$ & $78(35)$ & $0.193 \S$ \\
\hline Mean years of hormone replacement therapy & $1.6(3.7)$ & $1.9(4.0)$ & $0.460^{*}$ \\
\hline Family history of ovarian cancer (\%) & $8(8)$ & $10(4)$ & $0.241 \S$ \\
\hline History of benign breast disease (\%) & $15(15)$ & $105(47)$ & $0.000 \S$ \\
\hline Family history of breast cancerf (\%) & $16(15)$ & $35(16)$ & $0.997 \S$ \\
\hline \multicolumn{4}{|l|}{ Units of alcohol/week (\%): } \\
\hline 0 & $38(36)$ & $59(26)$ & \multirow{4}{*}{$0.927 \ddagger$} \\
\hline $0-4$ & $26(25)$ & $71(31)$ & \\
\hline $5-9$ & $20(19)$ & $52(23)$ & \\
\hline$\geqslant 10$ & $22(21)$ & $44(20)$ & \\
\hline \multicolumn{4}{|l|}{ No of cigarettes/day: } \\
\hline 0 & $83(78.3)$ & $170(75.2)$ & \multirow{3}{*}{$0.383 \ddagger$} \\
\hline $1-9$ & $8(7.6)$ & $14(6.2)$ & \\
\hline$\geqslant 10$ & $15(14.2)$ & $42(18.6)$ & \\
\hline Body mass index $\left(\mathrm{kg} / \mathrm{m}^{2}\right)$ & $26.8(5.5)$ & $24.8(4.2)$ & $0.001^{*}$ \\
\hline
\end{tabular}

*Two sample $t$ test.

†Data for one case missing.

$\ddagger \chi^{2}$ test for trend.

$\S \chi^{2}$ test

qNo data for one control. usual convention in recording those events rated 1 or 2 and those difficulties rated 1 to 3 as severe.

The associations of prolonged periods of severe stress and prolonged periods of severe health problems with the onset of breast cancer were also examined. Severe difficulties, excluding the participant's own health problems, lasting 2 years or more were recorded as a third category ( "severe 2 year nonpersonal health difficulties"). A fourth category, "severe 2 year personal health difficulties," was recorded. We excluded events and difficulties that were related to ovarian cancer, past and present breast problems, or a first degree relative's breast or ovarian cancer.

\section{Analysis}

We performed univariate analysis to calculate odds ratios and to examine the predictive effect of each factor on the risk of breast cancer. Those risk factors that were significant $(\mathrm{P}<0.25)$ were entered into a forward selection multivariate logistic regression analysis, ${ }^{12}$ either as continuous variables or categorised as quartiles.

\section{Results}

\section{Participants and non-participants}

In total, 409 women were eligible for our study. Ten women were not interviewed; six had severe mental or physical illness and four had poor English. Overall, 333 of 399 women agreed to participate (84\%). We excluded one woman diagnosed with a lymphoma. One hundred and six women (32\%) were diagnosed with breast cancer and $226(68 \%)$ with benign breast disease. Forty six women (32 cancer, 14 benign) had been given a tissue diagnosis by the time of the interview

Of the 66 women who refused to participate, 18 $(27 \%)$ were diagnosed with cancer and $48(73 \%)$ with benign breast disease. No significant difference was found between participants and non-participants in the proportion of cancer and benign diagnoses, or in the age of cases or controls. There was no significant difference in the diagnoses of the women interviewed by each of the investigators.

Factors

Table 1 shows the characteristics of the cases and controls. Table 2 shows the risk factors for breast cancer, which were identified as potential confounders and entered into the multivariate analysis. The main risks for breast cancer were increasing age, postmenopausal status, later menopause, and increased body mass index. Factors associated with benign disease were history of benign breast lumps and exposure to the oral contraceptive pill. Factors that might have been expected to be associated with breast cancer but which were not were family history of breast cancer, nulliparity, and early menarche.

\section{Stressors}

Table 3 shows the final model, which includes results for the four categories of life stress. The most important risk factors for breast cancer were increasing age, increasing body mass index, and increasing alcohol consumption. Factors that predicted 


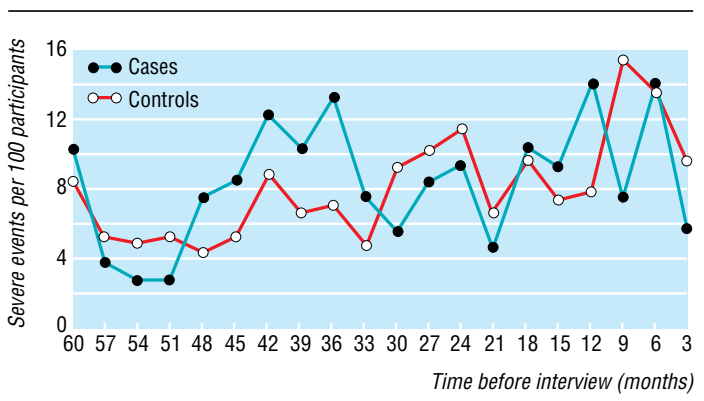

Rates of reporting of severe life events in 3 month intervals from time of interview over 5 years

benign disease were history of benign breast lumps and exposure to hormone replacement therapy. Women diagnosed with malignant breast lump were no more likely to have experienced any of the stressors than women diagnosed with benign lumps or normal breasts.

\section{Severe life events}

We wondered whether a severe life event or a mood disorder around the time of clinical presentation could affect the presenting behaviour of the control group. ${ }^{13}$ If there were high rates of severe life events among the control group this might obscure a relation between breast cancer and severe life events when one existed. We found no evidence of an increase in severe life events among controls before clinical presentation (fig). Because the events and difficulties we have identified are known to be associated with the onset of depressive disorders, we examined depression in the two groups. For those who were unaware of their diagnosis at the time of interview, scores on the Beck depression inventory were the same in both groups (mean $8.6 v 8.5, \mathrm{t}=0.04, \mathrm{df}=281, \mathrm{P}=0.97)$. Seven $(7 \%)$ cases and $21(9 \%)$ controls were taking an antidepressant at the time of the interview $\left(\chi^{2}=0.67, \mathrm{df}=1\right.$, $\mathrm{P}=0.411)$. This suggests that the experience of life events of women before diagnosis had been the same in both groups.

We noted a larger proportion of controls (47\%) than cases $(14 \%)$ who reported a history of benign breast lump requiring tissue diagnosis. Had there been a relation between severe life events and recurring benign breast lumps this might have concealed a relation between severe life events and cancer when one existed. Further analysis showed that experience of one or more severe life events was not significantly associated with a history of benign breast lump (odds ratio $0.73,95 \%$ confidence interval 0.46 to 1.16 ; $\mathrm{P}=0.182)$.

Forty two of $70(60 \%)$ women who either knew or predicted they had cancer reported one or more severe life events in the study period compared with 132 of $213(62 \%)$ who knew or predicted they had a benign lump $\left(\chi^{2}=0.084\right.$, $\left.\mathrm{df}=1, \mathrm{P}=0.77\right)$. The reporting of severe life events decreased over time. The decay in reporting severe events per 100 participants per quarter was 0.207 for cases and 0.208 for controls. The difference was not significant $(\mathrm{t}=0.02, \mathrm{P}=0.98)$. These calculations suggest that attempts by the women to explain their diagnosis by searching for stresssometimes called effort after meaning ${ }^{4}$-was not an important source of reporting bias.
Table 2 Odds ratios (95\% confidence interval) of risk factors for breast cancer derived from univariate analysis entered into multivariate analysis

\begin{tabular}{|c|c|c|}
\hline Risk factor & Odds ratio $(95 \% \mathrm{Cl})$ & $P$ value \\
\hline \multicolumn{3}{|l|}{ Age (years) v 40-49 years: } \\
\hline $50-59$ & 1.79 (0.91 to 3.53$)$ & $0.000^{*}$ \\
\hline $60-69$ & 10.68 (5.12 to 22.30$)$ & $0.000^{*}$ \\
\hline $70-79$ & 16.40 (7.26 to 37.03$)$ & $0.000^{*}$ \\
\hline History of benign breast lumps & 0.19 (0.10 to 0.35$)$ & $0.000^{*}$ \\
\hline \multicolumn{3}{|l|}{ Months breast feeding $v$ no breast feeding: } \\
\hline $0.5-8$ & $1.56(0.88$ to 2.77$)$ & $0.124^{*}$ \\
\hline$>8$ & 1.28 (0.74 to 2.22$)$ & 0.384 \\
\hline \multicolumn{3}{|l|}{ Menopausal status $v$ premenopausal: } \\
\hline Perimenopausal & 0.99 (0.39 to 2.48$)$ & 0.977 \\
\hline Postmenopausal & 3.34 (1.76 to 6.35$)$ & $0.000^{*}$ \\
\hline \multicolumn{3}{|l|}{ Age at menopause $v$ premenopausal: } \\
\hline $28-40$ & 1.54 (0.59 to 3.99$)$ & 0.377 \\
\hline $41-49$ & 2.81 (1.47 to 5.37$)$ & $0.002^{*}$ \\
\hline$>50$ & $5.82(2.85$ to 11.85$)$ & $0.000^{*}$ \\
\hline \multicolumn{3}{|l|}{ Age at hysterectomy $v$ no hysterectomy: } \\
\hline $27-42$ & 0.39 (0.16 to 0.98$)$ & $0.045^{*}$ \\
\hline$>43$ & $1.72(0.87$ to 3.37$)$ & $0.117^{*}$ \\
\hline Ever had hormone replacement therapy & $0.71(0.43$ to 1.19$)$ & $0.194^{*}$ \\
\hline \multicolumn{3}{|c|}{ Years of hormone replacement therapy $v$ never had hormone replacement therapy: } \\
\hline $0.2-4.5$ & $0.64(0.32$ to 1.27$)$ & $0.203^{*}$ \\
\hline $5.0-24.0$ & $0.79(0.41$ to 1.50$)$ & 0.470 \\
\hline Past use of oral contraceptive pill & $0.39(0.24$ to 0.62$)$ & $0.000^{*}$ \\
\hline \multicolumn{3}{|c|}{ No of years taking oral contraceptive pill $v$ never taken oral contraceptive pill: } \\
\hline $0.25-6.5$ & 0.35 (0.19 to 0.62$)$ & $0.000^{*}$ \\
\hline $7.0-22.0$ & $0.44(0.24$ to 0.79$)$ & $0.007^{\star}$ \\
\hline \multicolumn{3}{|l|}{ Body mass index $\left(\mathrm{kg} / \mathrm{m}^{2}\right) \vee 17.0-22.0 \mathrm{~kg} / \mathrm{m}^{2}$ : } \\
\hline $22.1-24.2$ & $0.67(0.50$ to 0.97$)$ & $0.008^{*}$ \\
\hline $24.3-47.0$ & $1.46(1.08$ to 1.97$)$ & $0.013^{*}$ \\
\hline \multicolumn{3}{|l|}{ Units of alcohol/week $v 0$ units/week: } \\
\hline $1-4$ & $0.57(0.31$ to 1.04$)$ & $0.068^{*}$ \\
\hline $5-9$ & $0.60(0.31$ to 1.15$)$ & $0.124^{*}$ \\
\hline$\geqslant 10$ & 0.78 (0.40 to 1.49$)$ & 0.448 \\
\hline
\end{tabular}

${ }^{*} \mathrm{P}<0.25$; variable entered into multivariate analysis.

Table 3 Final main effects model of risk factors for cancer

\begin{tabular}{lcc} 
Covariate & Odds ratio $(\mathbf{9 5 \%} \mathbf{C l})$ & P value \\
\hline History of benign breast disease $v$ no history $(\mathrm{n}=120)$ & $0.25(0.13$ to 0.50$)$ & 0.000 \\
\hline Age $($ years $)$ & $1.12(1.08$ to 1.15$)$ & 0.000 \\
\hline Body mass index $\left(\mathrm{kg} / \mathrm{m}^{2}\right)$ & $1.08(1.01$ to 1.14$)$ & 0.017 \\
\hline Ever had hormone replacement therapy $(\mathrm{n}=107)$ & $0.54(0.29$ to 1.0$)$ & 0.05 \\
\hline Units alcohol/week $v$ non-drinkers: & & \\
\hline $0-4(\mathrm{n}=97)$ & $1.34(0.61$ to 2.96$)$ & 0.47 \\
\hline $5-9(\mathrm{n}=72)$ & $2.06(0.84$ to 5.05$)$ & 0.113 \\
\hline$\geqslant 10(\mathrm{n}=66)$ & $2.98(1.26$ to 7.06$)$ & 0.013 \\
\hline$\geqslant 1$ severe life event $(\mathrm{n}=212)$ & $0.91(0.47$ to 1.78$)$ & 0.79 \\
\hline 4 week difficulty $(\mathrm{n}=134)$ & $0.86(0.41$ to 1.81$)$ & 0.69 \\
\hline 2 year non-personal health difficulty $(\mathrm{n}=40)$ & $0.53(0.12$ to 2.31$)$ & 0.39 \\
\hline 2 year personal health difficulty $(\mathrm{n}=56)$ & $2.72(0.68$ to 10.9$)$ & 0.16 \\
\hline
\end{tabular}

\section{Discussion}

\section{Possible sampling bias}

Case-control studies are notoriously susceptible to bias. We have tried to reduce sampling bias by recruiting from all three clinics serving a defined catchment area, and by making an initial contact with participants in the breast clinic so that losses and refusals were kept to a minimum. Even so we cannot be sure that our controls were representative of all women with benign breast disorders. Such women had, for example, the same rates of family history of breast cancer as the cancer group, probably because this increased the chances of an apparently benign lump being biopsied. Alterna- 
Key messages

- Although there is widespread belief that stress can cause cancer, research evidence is contradictory

- Stressful life experiences are common; about two thirds of women with a breast lump experienced at least one severe life event or difficulty in the 5 years before presentation

- Women diagnosed with breast cancer were no more likely to have experienced a severe stressor than women with a benign lesion

- Knowledge or suspicion of the diagnosis did not influence reporting of severe life events

tively, they may have been referred to the clinic, or biopsied, because of a recent life stress. Our other results do not support the inference of serious bias in selection of cases or controls.

\section{Confounding}

The main potential bias comes from age being a confounder-there was a 10 year difference in age between women with benign and malignant disease. We dealt with this by adjusting for age in the multivariate analysis rather than by recruiting a second sample from the general population, because the latter approach introduces other potential biases, due mainly to difficulties in recruitment for research in life events from community samples.

\section{Other biases}

To reduce reporting and measurement bias, we used two interviewers and ensured that borderline events and difficulties were rated at consensus meetings, and that equivocal stressors were rated by a third person unaware of the diagnosis. In addition we avoided subgroup reanalysis, ${ }^{14}$ restricting our study to the association between onset of breast cancer and the experience of four types of stressor, which were specified before data were collected.

\section{Conclusion}

Our data provide no support for the theory that severe life stresses may be concerned with the cause of breast cancer. This finding agrees with the results of a recent meta-analysis of observational studies examining the relation of life events to risk of breast cancer; the authors found evidence of bias in the literature, but larger and better quality studies showed no association between breast cancer and bereavement or other severe life events. ${ }^{15}$ We believe that women with breast cancer can be told that life stresses are unlikely to have played an important part in the development of their disease. The issue of stress and breast cancer relapse is unresolved.

We thank David Dodwell for invaluable help and encouragement setting up the study, Tirril Harris for advice and help with consensus ratings, and Jenny Barratt for additional statistical advice. We thank the nursing and administrative staff at all three hospitals for their help, and the participants.

Contributors: DP conceived the idea, designed the study with $\mathrm{AH}$, and conducted and rated the interviews with $\mathrm{KT}$. KH and $\mathrm{EB}$ advised on confounding variables and logistical problems, explained the study to their patients, and obtained initial consent. DB gave statistical advice and performed the analyses. DP and AH wrote the paper; they will act as guarantors for the paper.

Funding: Cookridge Hospital trust funds at the Yorkshire centre for clinical oncology, and the Ivy Hobson bequest.

Competing interests: None declared.

1 LeShan L. Psychological states as factors in the development of malignant disease: a critical review. J Natl Cancer Inst 1959;22:1-18.

2 Baghurst KI, Baghurst PA, Record SJ. Public perceptions of the role of dietary and other environmental factors in cancer causation or prevention. J Epidemiol Comm Health 1992:46:120-6.

3 McGee R, Williams S, Elwood M. Are life events related to the onset of breast cancer? Psychol Med 1996;26:441-7.

4 Brown GW, Harris TO. The social origins of depression: a study of psychiatric disorder in women. London: Tavistock, 1978

5 Ramirez A, Craig TKJ, Watson JP, Fentiman IS, North, WRS, Rubens RD. Stress and relapse of cancer. BMJ 1989;298:291-3.

6 Barraclough J, Pinder P, Cruddas M, Osmond C, Taylor I, Perry M. Life events and breast cancer prognosis. BMJ 1992;304:1078-81.

7 Geyer S. Life events prior to manifestation of breast cancer: a limited prospective study covering eight years before diagnosis. J Psychosom Re 1991;35:355-63.

8 Chen CC, David AS, Nunnerley H, Michell M, Dawson JL, Berry H, et al. Adverse life events and breast cancer: a case control study. BMJ 1995;311:1527-30.

9 Reed MJ, Ghilchik MW. Association may be due to imbalance in ratio of adrenal androgen to glucocorticoid. BMJ 1996;312:845

10 Cassileth BR. Stress and the development of cancer. Cancer 1996;77:1015-16.

11 Beck AT, Ward CH, Mendelson M, Mock J, Erbaugh J. An inventory for measuring depression. Arch Gen Psych 1961;4:561-85.

12 Hosmer DW, Lemeshow S. Model building strategies and methods for logistic regression. In: Applied logistic regression. New York: John Wiley, 1989.

13 Mechanic D. Social psychologic factors affecting the presentation of bodily complaints. N Engl J Med 1972;286:1132-9

14 Counsell CE, Clarke MJ, Slattery J, Sandercock PAG. The miracle of DICE therapy for acute stroke: fact or fictional product of subgroup analysis? BMJ 1994;309:1677-81.

15 Petticrew M, Fraser JM, Regan MF. Adverse life-events and risk of breast cancer: a meta-analysis. Br J Health Psychol 1999;4:1-17.

(Accepted 21 June 1999)

\section{One hundred years ago}

\section{A case of tetany due to exposure to the sun}

A boy, aged 13, was brought to me by his mother and a friend, complaining of pains in his arms and legs, and inability to move his hands and feet. He was one of a large and healthy family, and had never suffered from any illness until the day before I saw him. He had been sitting in the sun all the preceding afternoon, and on reaching home complained of headache and vomited. He was sent to bed, and woke up about 5 a.m., complaining of pains in his arms and legs, and that he could not move. He was brought to the surgery at 9 a.m., when it was seen that the hands and feet were rigidly contracted in the position met with in tetany, and he was quite unable to move them. His knee-jerks were markedly exaggerated. He was very nervous and frightened, but apart from the conditions of his hands and feet appeared in good health.

There was not, nor had there been, any gastric or intestinal trouble. He was treated with a calomel purgative and 10 gr. doses of ammonium bromide every four hours. The spasm gradually relaxed, but it was five days before he could walk or use his hands properly. The case appeared interesting owing both to the age of the case patient and to the total absence of any cause for the attack that I could discover other than exposure to the sun, a somewhat unusual, or at least undescribed, cause of tetany. Catford S.E. Herbert Fox, M.B. Lond. (BMJ 1899;ii:1474) 